\title{
USO DE ÁRVORES E ARBUSTOS EM CIDADES BRASILEIRAS
}

José Hamilton de Aguirre Junior ${ }^{1}$, Ana Maria Liner Pereira Lima ${ }^{2}$

O objetivo deste trabalho é demonstrar através de imagens e discussões que a substituição generalizada de árvores de médio e grande porte por arbustos nas cidades brasileiras, fenômeno a cada dia mais observado, é uma medida que deveria ser repensada pelo gestor público e cidadãos devido à conseqüente redução da qualidade de vida e dos benefícios financeiros antes propiciados pela cobertura arbórea com árvores de médio e grande porte. As imagens utilizadas coletadas nas cidades de Piracicaba/SP, Campinas/SP e Maringá/PR, permitem uma avaliação das vantagens e das conseqüências que o uso racional da arborização proporciona, além de comparar as condições de locais mais e menos arborizados.

${ }^{1}$ Engenheiro Florestal, Mestrando em Agronomia, ESALQ/USP, jhaguirr@gmail.com

2 Engenheira Agrônoma, professora doutora, ESALQ/USP, amlplima@esalq.usp.br 


\section{Considerações gerais}

Do ponto de vista técnico, arbustos são vegetais com:

- Estruturas lenhosas ou semi-lenhosas

- 3- $6 m$ de altura

- Ramificados desde sua base (MASCARÓ e MASCARÓ, 2005)

\section{ARBUSTOS}
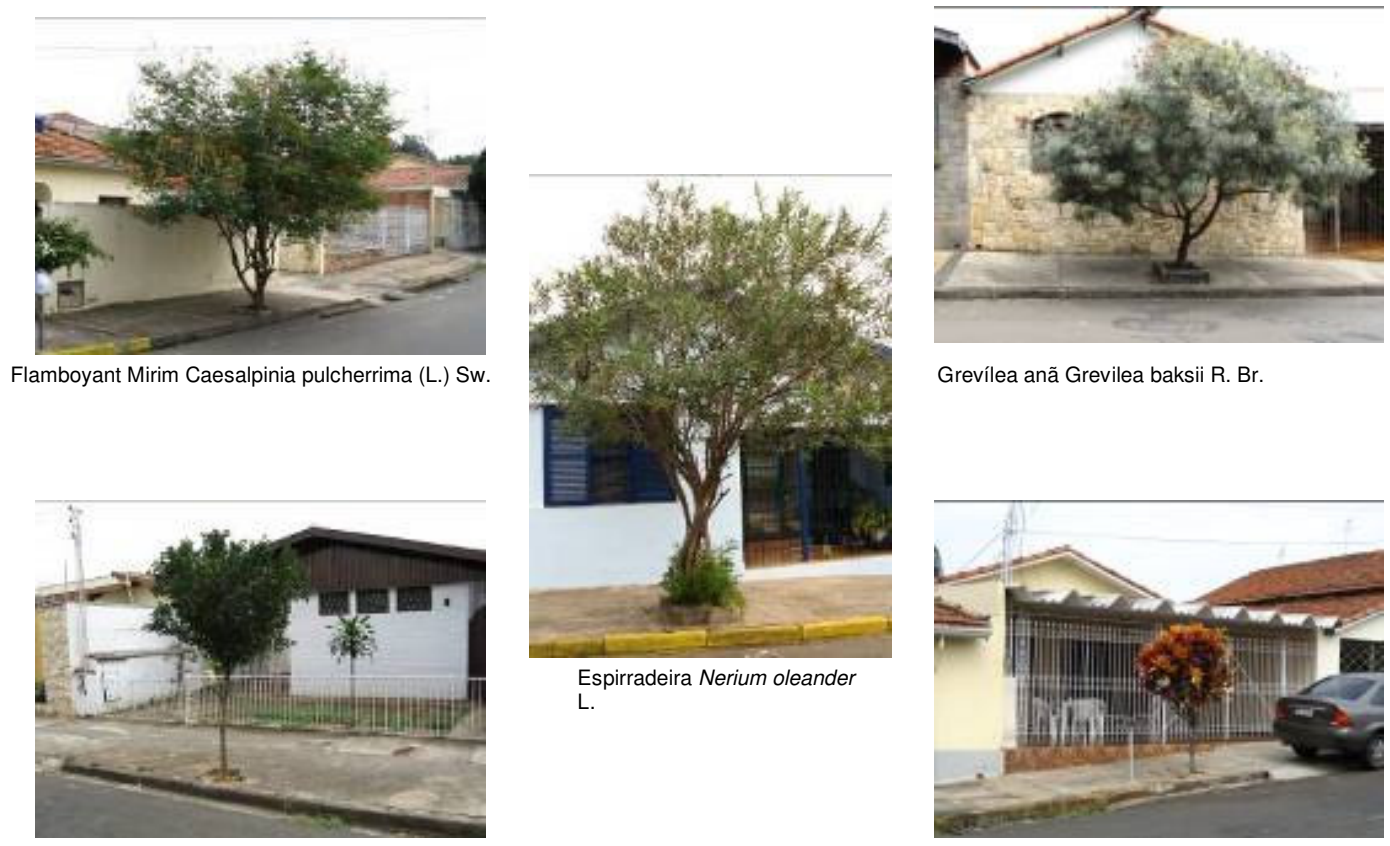

Grevílea anã Grevilea baksii R. Br.

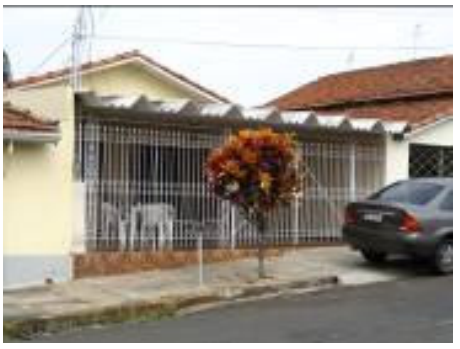

Cróton Codiaeum variegatum (L.) A. Juss. 
Já as árvores, possuem fuste (tronco) único, lenhoso e dividem-se pelo seu porte:

- Pequeno, para alturas entre $(4-6 \mathrm{~m})$ e copas $(<4 \mathrm{~m})$;

- Médio, para alturas entre (6-10m) e copas entre (4-6m);

- Grande, para alturas $(>10 \mathrm{~m})$ e copas com dimensões $(>6 \mathrm{~m})$ (MASCARÓ e MASCARÓ, 2005)

\section{ÁRVORES}

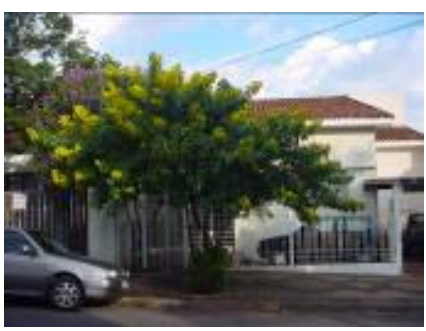

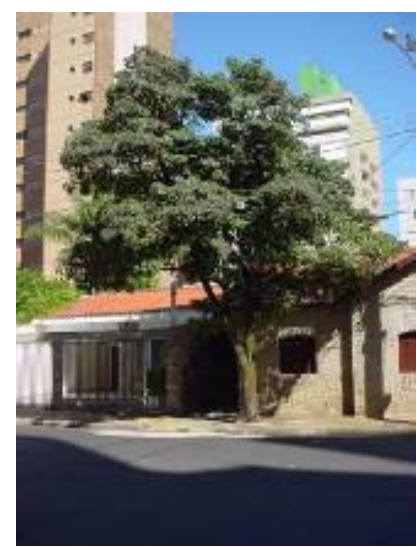

Médio Porte:

Ipê Branco Tabebuia roseo alba (Ridl.) Sand.

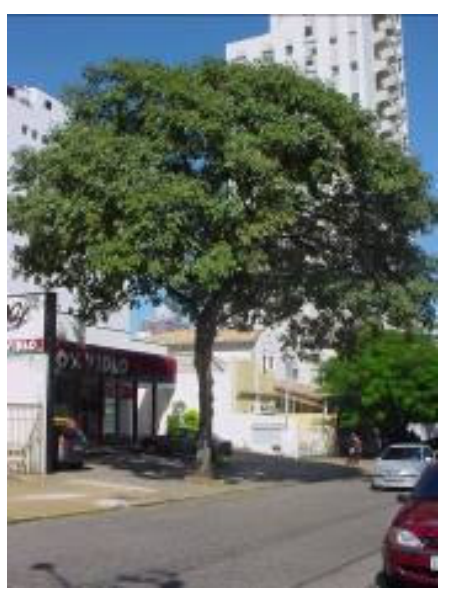

Grande Porte:

Ipê Roxo Tabebuia impetiginosa (Mart. ex DC.) Standl.

Dentre as inúmeras vantagens obtidas pela utilização de árvores de médio e grande porte nas cidades destacadas por vários autores estão:

- redução de temperatura pela cobertura de superfícies refletoras de calor - Árvores de copa rala interceptam de 60 a $80 \%$ da radiação direta incidente e as de copa espessa até $98 \%$ da radiação direta (HEISLER, 1974 apud GREY; DENEKE, 1978);

- sombreamento e conservação do asfalto - cada $\mathrm{m}^{2}$ de asfalto coberto por copas reduz os gastos públicos com manutenção em R \$15,47/ano (SILVA FILHO, 2006);

- redução da velocidade das enxurradas pela retenção e liberação aos poucos da água das chuvas - algumas espécies de grande porte como a tipuana e a sibipiruna podem reter até $60 \%$ da água nas 2 primeiras horas de uma chuva, liberando-a aos poucos (SILVA et al., 2007);

- alta taxa de evapotranspiração, 400l diários, o que aumenta a umidade do ar e produz o mesmo efeito que 5 aparelhos de ar condicionado médios $(2500 \mathrm{kcal} / \mathrm{h})$ funcionando por $20 \mathrm{~h}$, 
todos os dias (GREY; DENEKE, 1978), sem gastar energia ou produzir calor como os equipamentos;

- ruas bem arborizadas podem reter até $70 \%$ da poeira em suspensão (BERNATZKY, 1980 apud GREY; DENEKE, 1978). Uma única fila de árvores pode reduzir os particulados em 25\% (WOOD, 1979 apud GREY; DENEKE, 1978), como é o caso da arborização viária.

\section{Necessidades específicas da presença de vegetação no meio urbano}

Nas cidades, devido ao alto grau de urbanização, caracterizado pela quase totalidade de superfícies impermeabilizadas, verticalização (prédios e construções), asfalto, superfícies acumuladoras e refletoras de calor, além da poluição e da alta concentração de população, a utilização de árvores de médio e grande porte é imprescindível para a mitigação dos efeitos causados pela ação humana sobre o meio. Elas podem reduzir a amplitude térmica e melhorar as condições microclimáticas na cidade e, consequentemente, a vida dos cidadãos. Os arbustos e árvores de pequeno porte, ao contrário, pelas próprias características intrínsecas destas espécies, não garantem os mesmos efeitos propiciados pelas árvores (Figura 1).

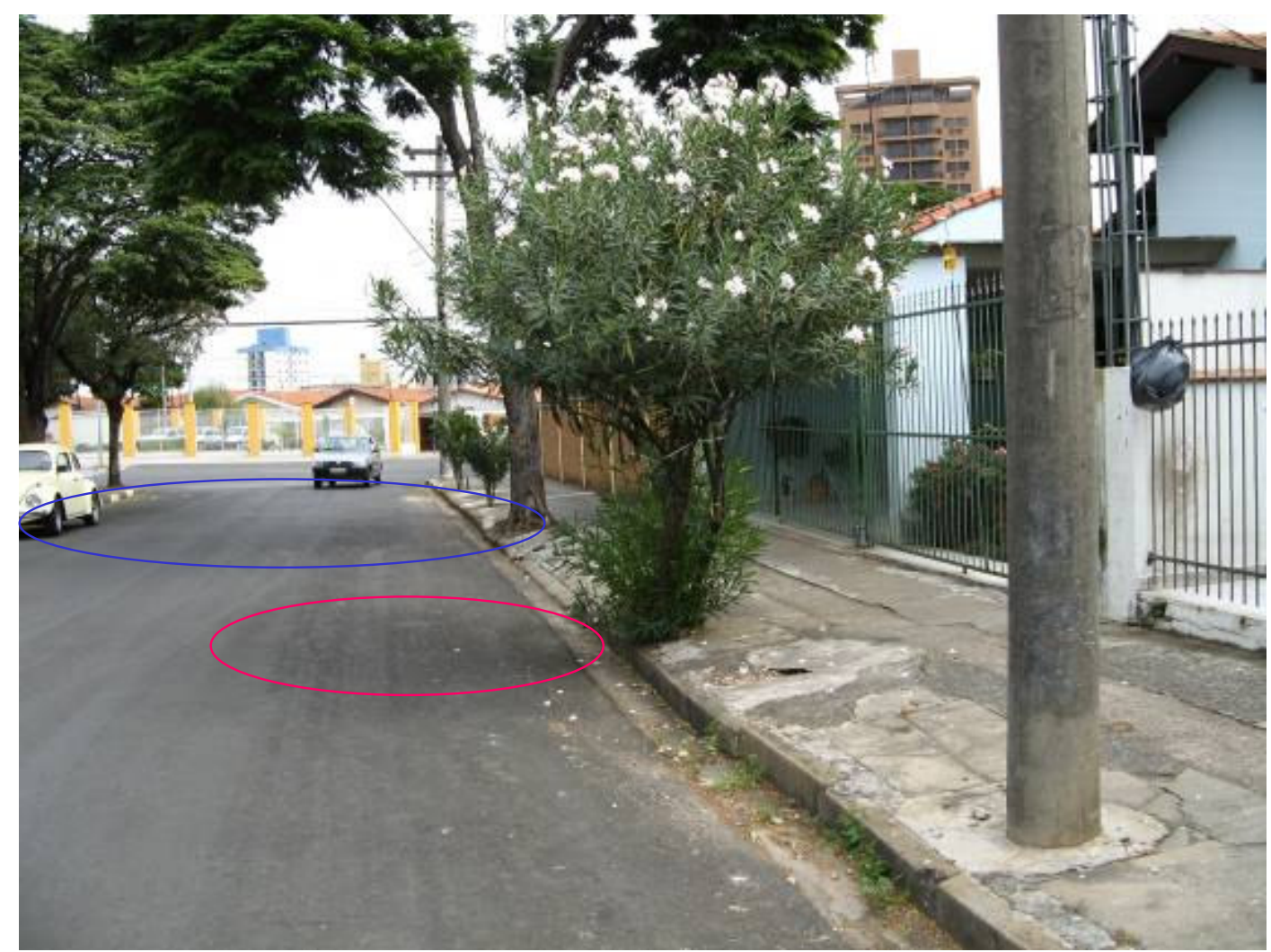

Figura 1. Em vermelho nota-se o sombreamento reduzido da espirradeira Nerium oleander L. em comparação ao propiciado pela espécie sibipiruna Caesalpinia pluviosa DC., em azul. 
Nota-se, também, a ramificação desde a base da primeira espécie, o que aumenta a necessidade de sua manutenção com podas em contraposição ao fuste (tronco) único da segunda, que não mais requer essa prática. Imagem coletada em Piracicaba/SP.

Os arbustos, inclusive, são prejudiciais no caso de calçadas estreitas devido à suas copas baixas e ramificações, que geram a competição do espaço do passeio público com o necessário à passagem dos pedestres. Suas copas estabelecem-se na mesma faixa de altura das janelas residenciais, formando bloqueios visuais aos moradores e impedindo a propagação da iluminação pública perdida pelo sombreamento das copas (Figura 2).
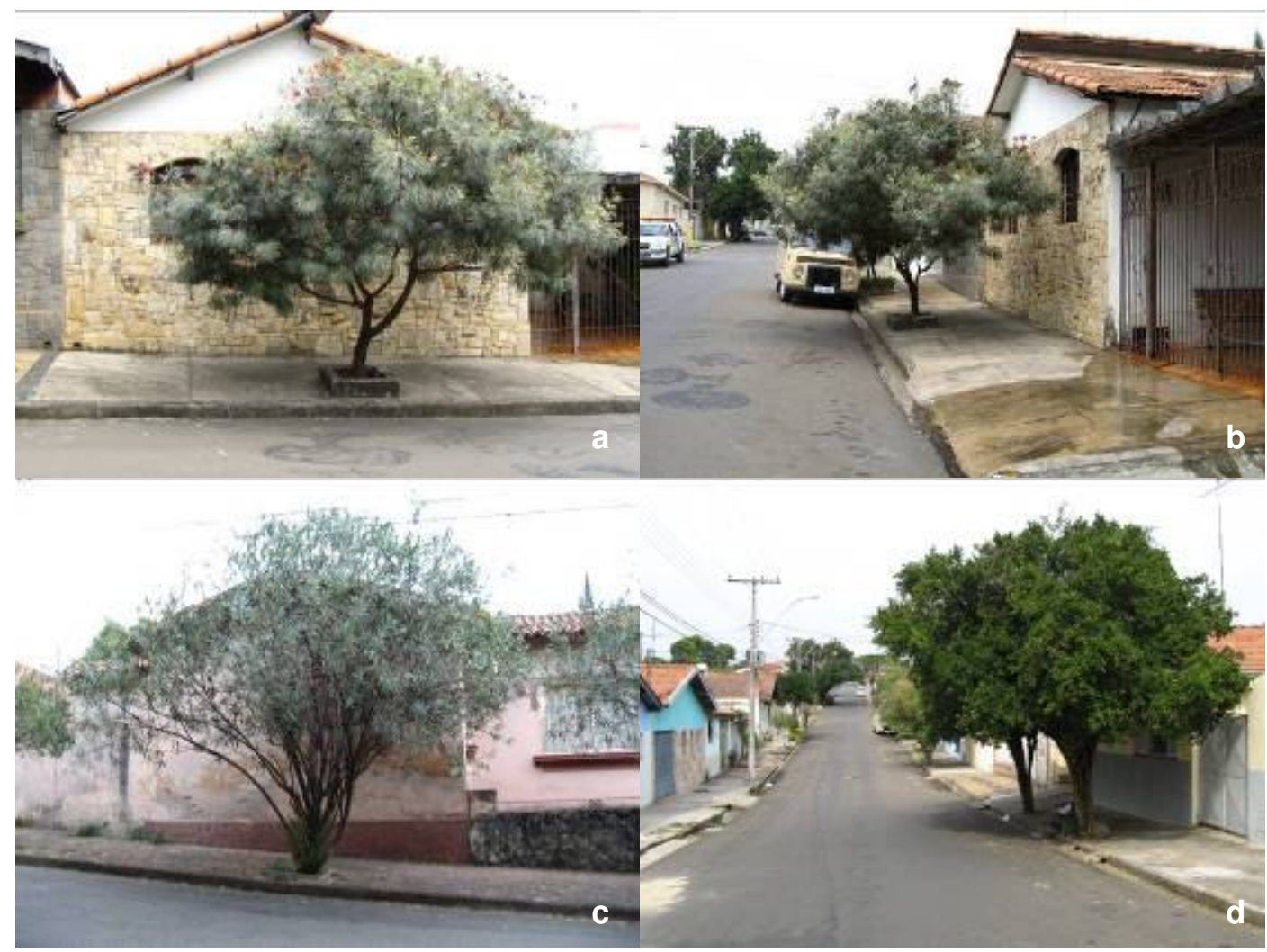

Figura 2. a, b, c e d - Bloqueio visual das janelas causados pela copa baixa de arbustos. b, c e d - Competição pelo espaço das calçadas das copas com os pedestres e obstrução da iluminação pública. Imagens coletadas em Piracicaba/SP.

No caso da utilização de árvores de grande porte em calçadas estreitas, esta se mostra muito mais prática e eficiente comparando-se aquela realizada com arbustos. Devese ressaltar a necessidade da realização da técnica adequada de plantio para não ocorrerem problemas causados pelas raízes (Figura 3). 




Figura 3. Calçada com 1,5m de largura arborizada com espécie de grande porte. O fuste único permite a livre passagem de pedestres ao contrário do que ocorre com o uso dos arbustos. Imagem coletada em Piracicaba/SP.

A utilização racional da arborização formando túneis pelo encontro das copas das árvores, proporciona um efeito paisagístico interessante, conduz o olhar do observador e gera microclimas agradáveis nas ruas, ao contrário daquelas que utilizam arbustos. Neste segundo caso, ocorre a desproporcionalidade entre as construções e a vegetação, a redução dos efeitos de benefício ambiental, além da má ocupação de uma área em que poderia estar plantada uma árvore. Locais em que haveria o potencial para o plantio de árvores, mas onde se utilizaram arbustos, são caracterizados pelo prejuízo ambiental e de microclima ao pedestre, tolhido do sombreamento, tão necessário em cidades de clima quente (Figuras 4 e 5 ). 


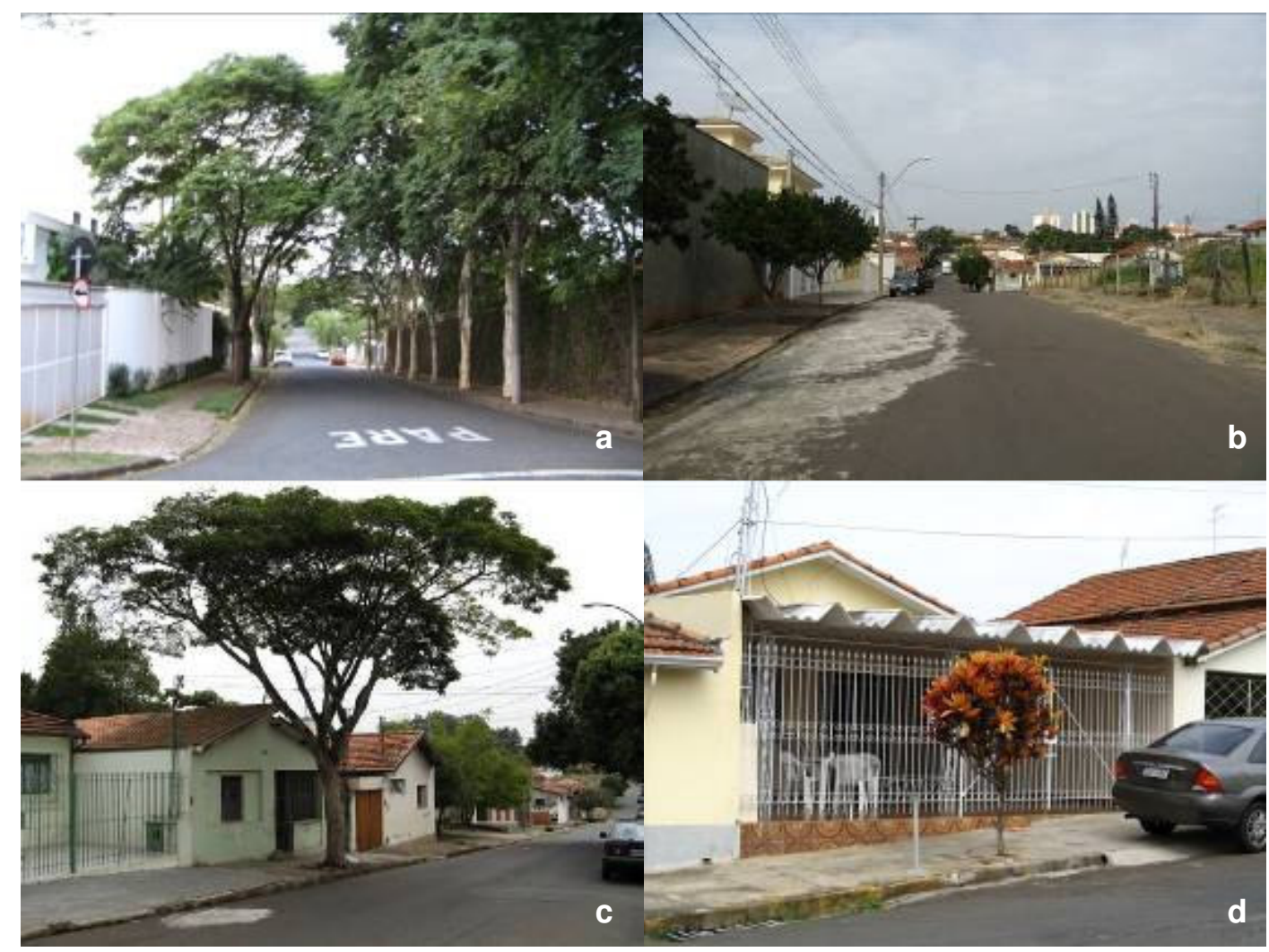

Figura 4. a - arborização viária formando túnel, conduzindo o olhar do observador, caracterizando perspectiva e proporcionalidade entre as construções. As espécies arbóreas utilizadas exercem influência positiva no microclima, no sombreamento e na conservação do asfalto, uma das principais superfícies refletoras de calor. b - Aspecto de uma rua parcialmente vegetada com arbustos acarretando em desproporcionalidade entre as construções e a vegetação, aridez local e conseqüente prejuízo na qualidade de vida dos moradores. $\mathrm{c}-\mathrm{A}$ árvore contribui mesmo que isoladamente. $\mathrm{d}$ - Ausência de contribuição dos arbustos. Imagens coletadas em Piracicaba/SP. 


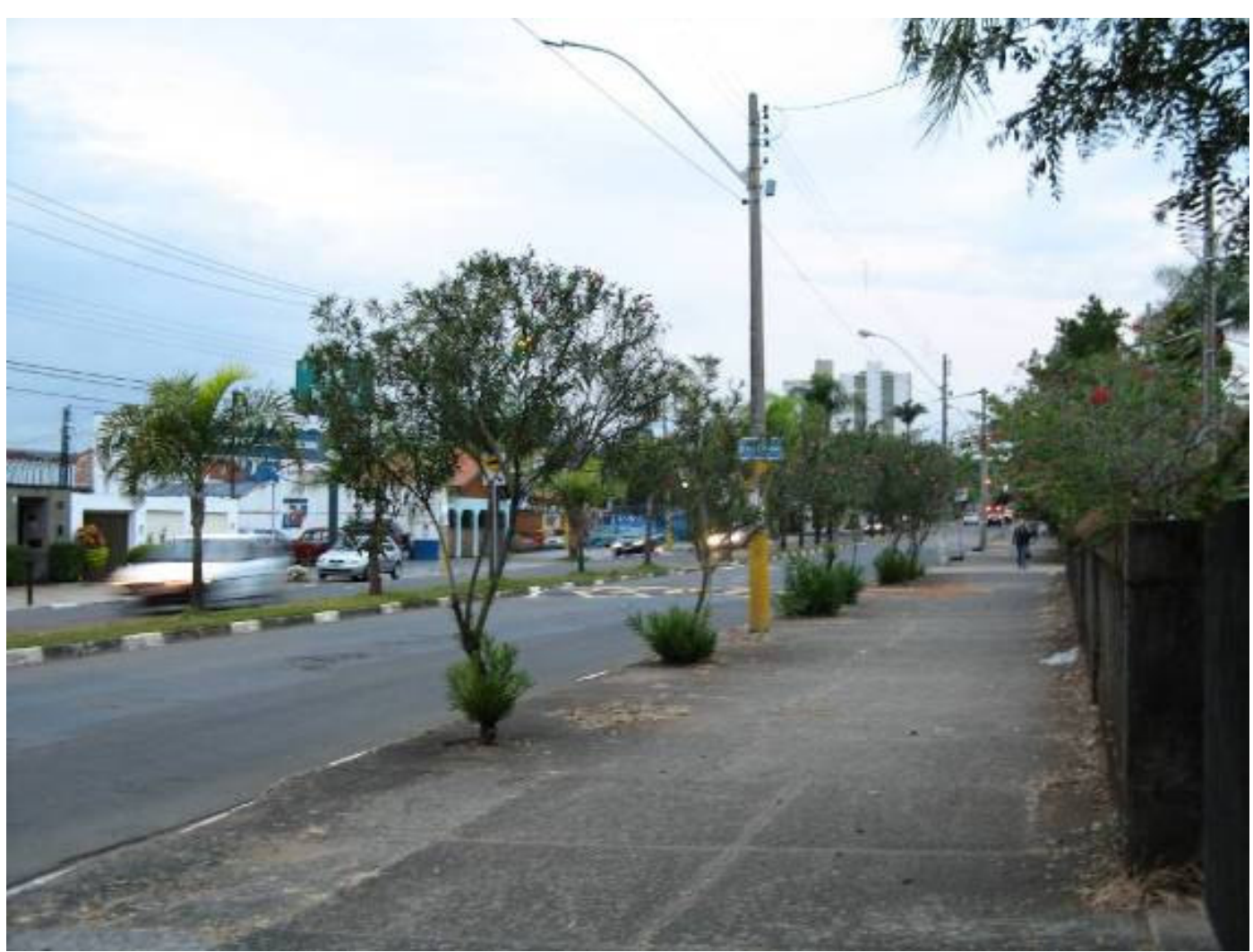

Figura 5. A utilização generalizada de arbustos em Piracicaba despreza a potencialidade local. Neste caso o recomendado e melhor para os pedestres seria a utilização de espécies arbóreas de grande porte. No entanto, as copas ralas e a constante rebrota dos arbustos, além de péssimo aspecto estético, priva os pedestres de sombreamento e de conforto térmico ao caminhar. Imagem coletada em Piracicaba/SP.

Piracicaba, cidade famosa no passado pela sua intensa arborização com espécies de grande porte, como destacado no trabalho de Lima (1993), que chegou a ter $56 \%$ do total da arborização da sua região central e entorno com indivíduos da espécie Sibipiruna Caesalpinia pluviosa DC., passou a retirar maciçamente suas árvores e não mais replantálas. O uso de espécies arbustivas a partir de então foi generalizado pela cidade. Nota-se nesta imagem a ausência quase total de vegetação, atualmente, no centro de Piracicaba (Figura 6). 


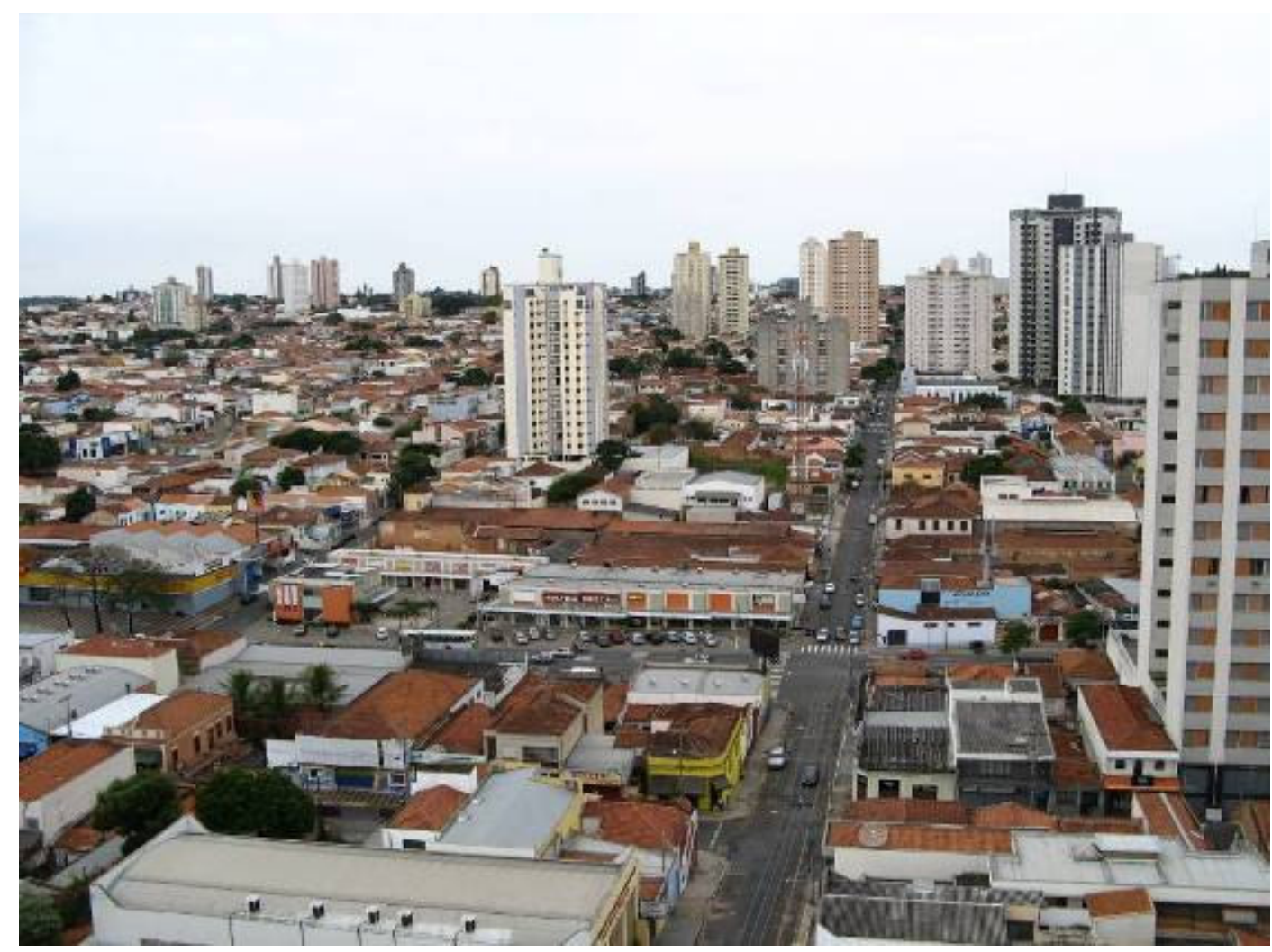

Figura 6. A retirada arbórea sem reposição e o uso de arbustos prejudicou a qualidade de vida dos habitantes de Piracicaba. Em seu centro, área extremamente pavimentada, construída e verticalizada, nota-se a aridez e os prejuízos ambientais para a população que vive na área.

Em Campinas, alguns dos bairros mais arborizados no passado, como é o caso do Cambuí e do Guanabara estão passando por uma intensa retirada arbórea. Porém, resta uma quantidade significativa de árvores de médio e grande porte que ainda produz efeitos ambientais relevantes. Nota-se, pela imagem do Bairro Cambuí, a convivência pacífica entre árvores de grande porte entremeadas por edifícios. As árvores reduzem a aridez, a poluição, adicionam umidade ao ar, são um elemento natural na paisagem, barram os raios refletidos pelas superfícies das construções e, assim, auxiliam na melhoria da qualidade de vida do homem urbano (Figuras 7 e 8 ). 


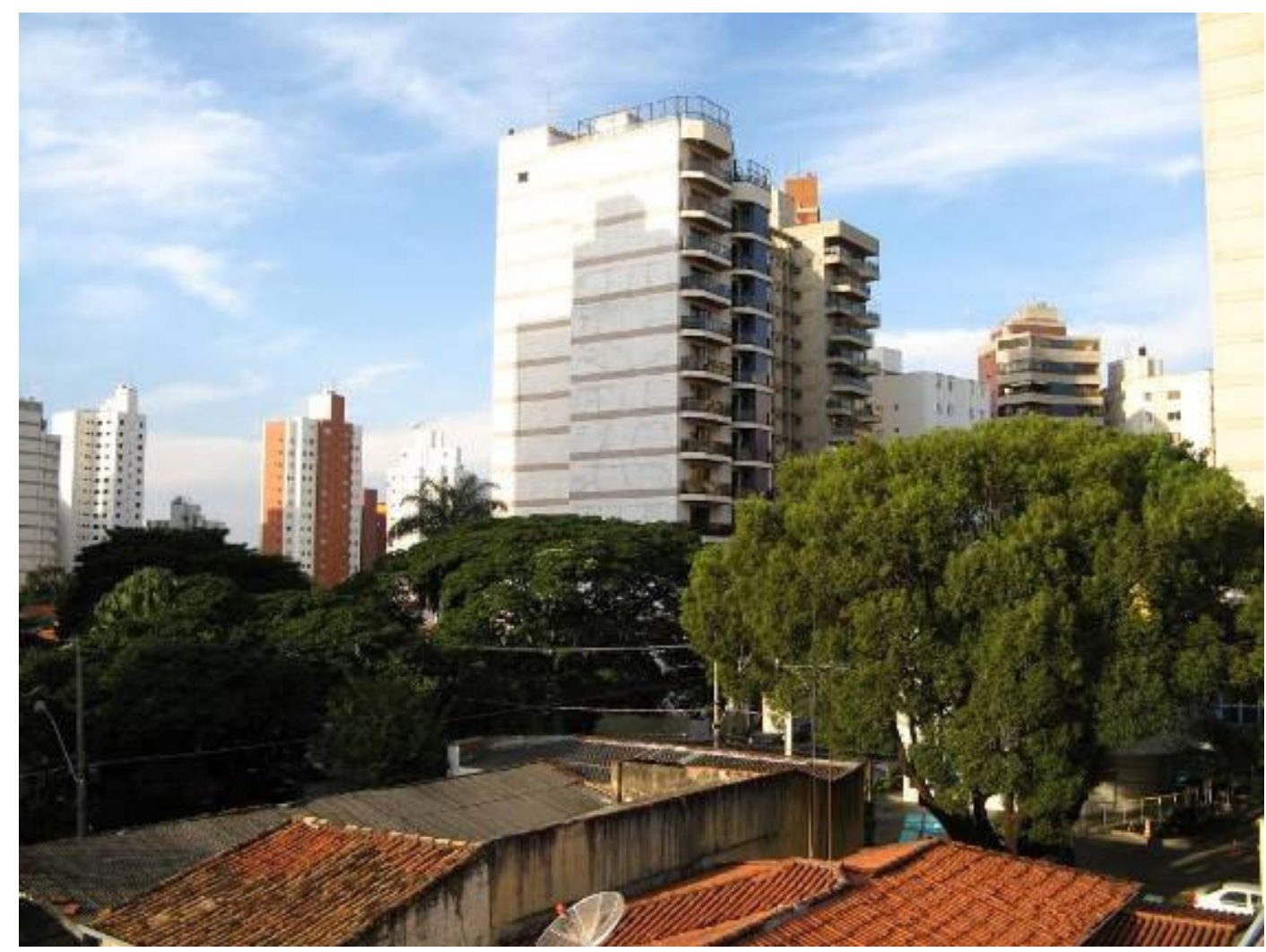

Figura 7. Aspecto da arborização do Bairro Cambuí, Campinas/SP. Nesta parte do bairro, nota-se a arborização de grande porte entremeada por edifícios e construções. 


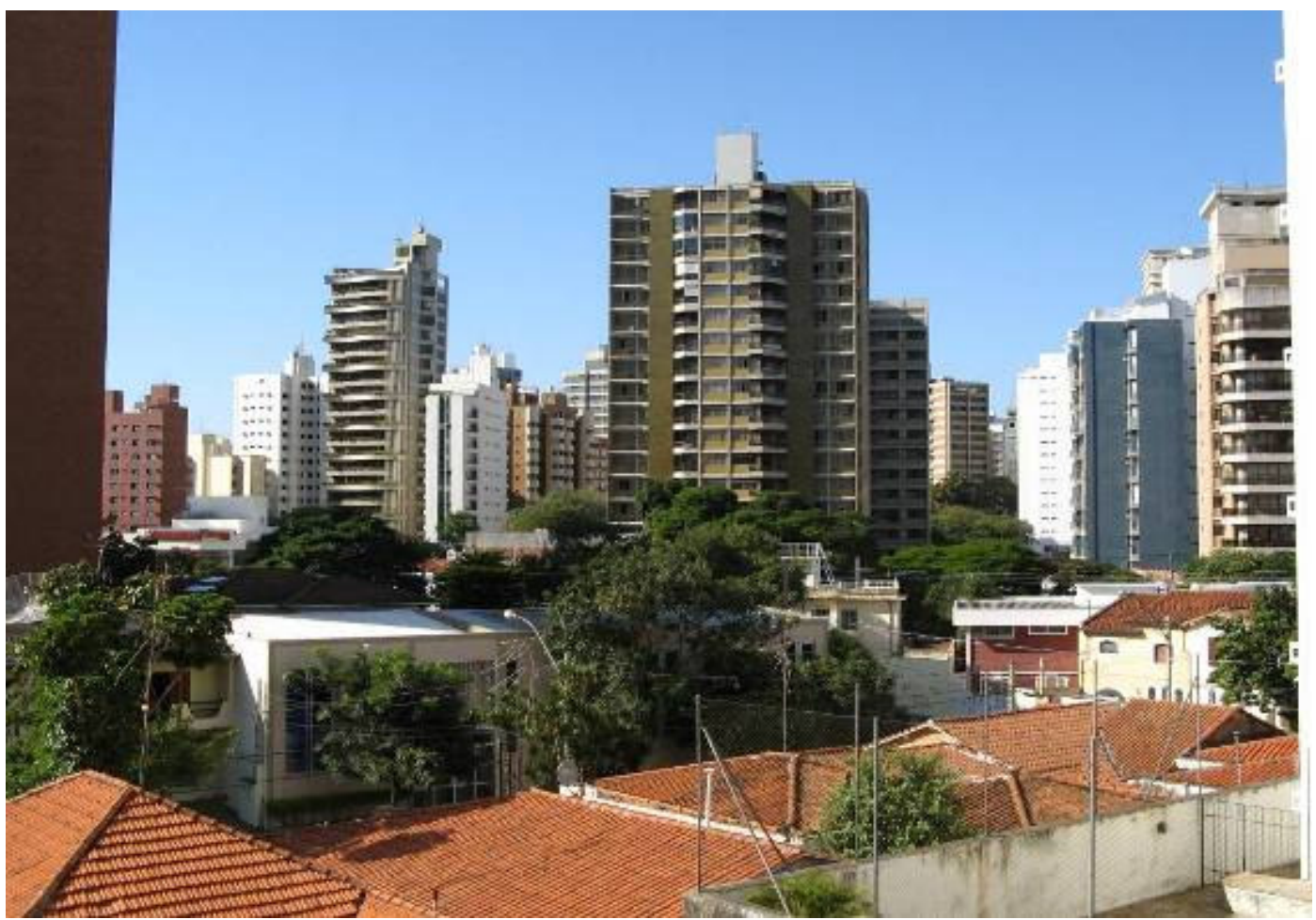

Figura 8. Arborização do Bairro Cambuí, Campinas/SP. A arborização de maior porte ajuda na mitigação da aridez e dos efeitos prejudiciais ao microclima proporcionado pela grande verticalização e áreas construídas.

A cidade de Maringá, localizada no estado do Paraná, com clima semelhante ao de Piracicaba, optou pela sua arborização total com espécies de porte elevado a fim de cobrir principalmente as superfícies asfaltadas e proporcionar sombra aos pedestres nas calçadas. Esta alternativa permitiu à cidade um ganho fabuloso em matéria de estética e de qualidade de vida a seus cidadãos. Hoje ela é um exemplo em matéria de arborização urbana para o Brasil, do aproveitamento da funcionalidade e da utilidade das árvores na melhoria e na estabilização do clima urbano (Figuras 9 e 10). 


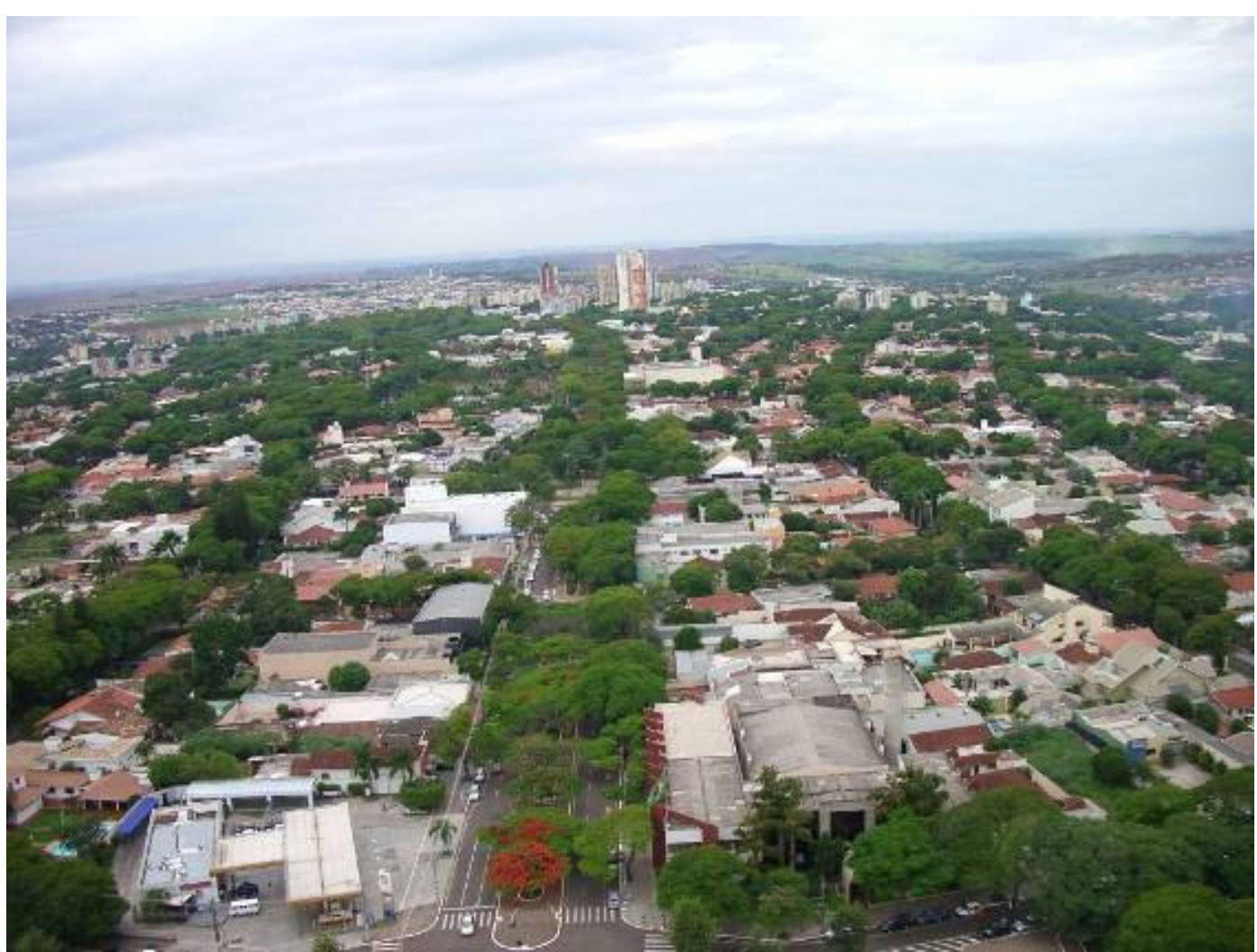

Figura 9. Aspecto da arborização viária de Maringá. Nota-se a formação de corredores que interligam a vegetação remanescente, a totalidade das ruas coberta pela copa das árvores, fator que deve ser ressaltado e servir de exemplo às cidades brasileiras. 


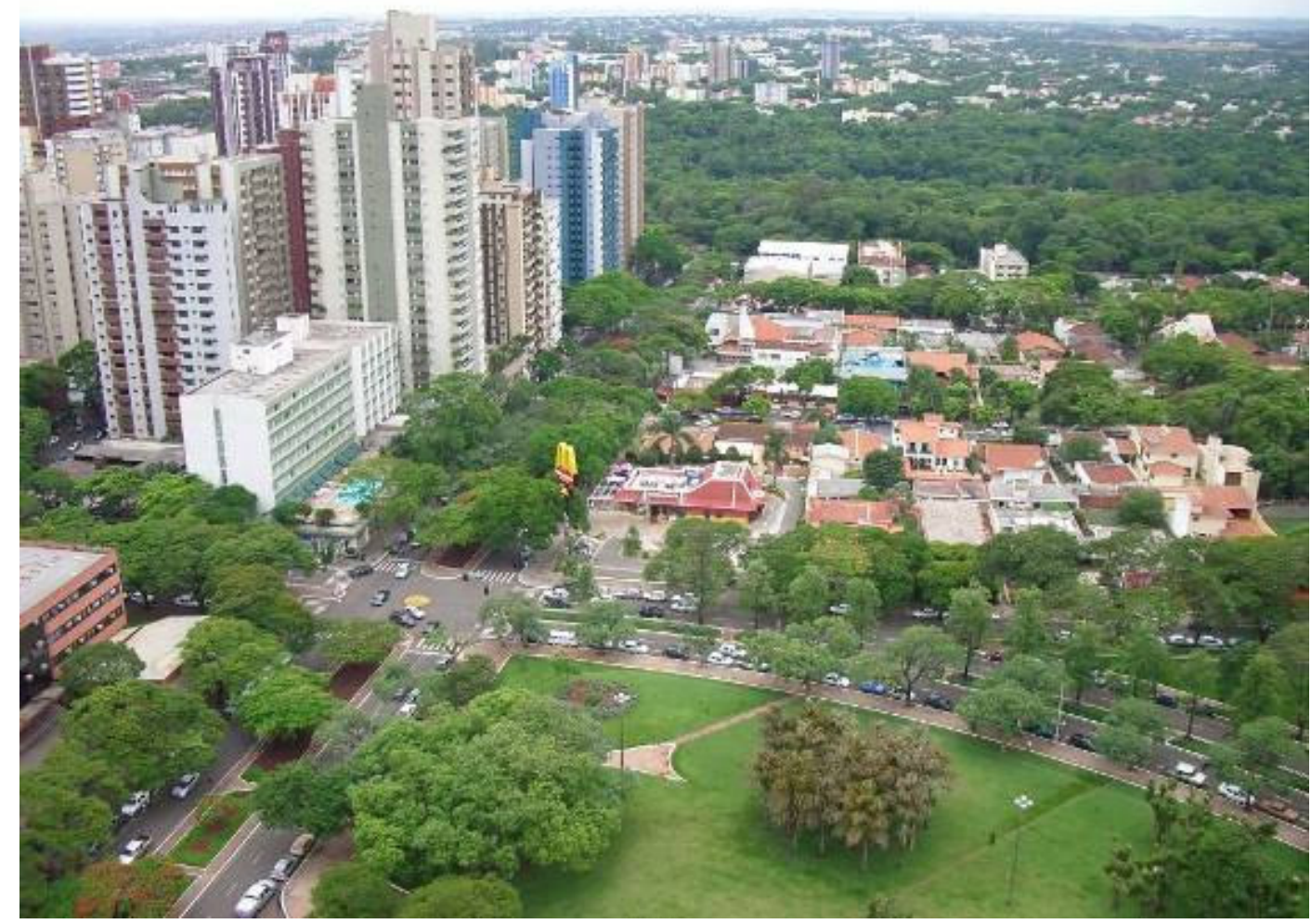

Figura 10. A presença de construções maiores convive harmoniosamente com a vegetação viária, dando à cidade paranaense um aspecto único pela confraternização entre o elemento construído e o natural.

\section{Fatores para a compatibilização da arborização no meio urbano}

Cidades como Maringá, optaram em rebaixar a iluminação pública e proteger os fios do sistema de distribuição de energia elétrica. A pressão da população ajudou para que a empresa concessionária de energia local, COPEL (Companhia Paranaense de Energia Elétrica), assumisse o compromisso de priorizar a conservação da arborização em seus empreendimentos. Este bom exemplo, mérito da empresa, uma das pioneiras na melhoria do seu sistema de distribuição, juntamente a CEMIG (Companhia Energética de Minas Gerais), deveria ser copiado pelas outras empresas do ramo, atuantes em todas as regiões do Brasil. Segundo Velasco (2003), as redes subterrâneas são altamente confiáveis e seu custo de implantação é amortizado em pouco tempo pela ausência de podas e reduzida necessidade de manutenção. Este é o desafio das empresas do ramo: o aterramento da fiação, de uma maneira adequada, que não prejudique o sistema radicular dos vegetais, ao mesmo tempo em que reduza os conflitos entre a arborização e redes de energia. 


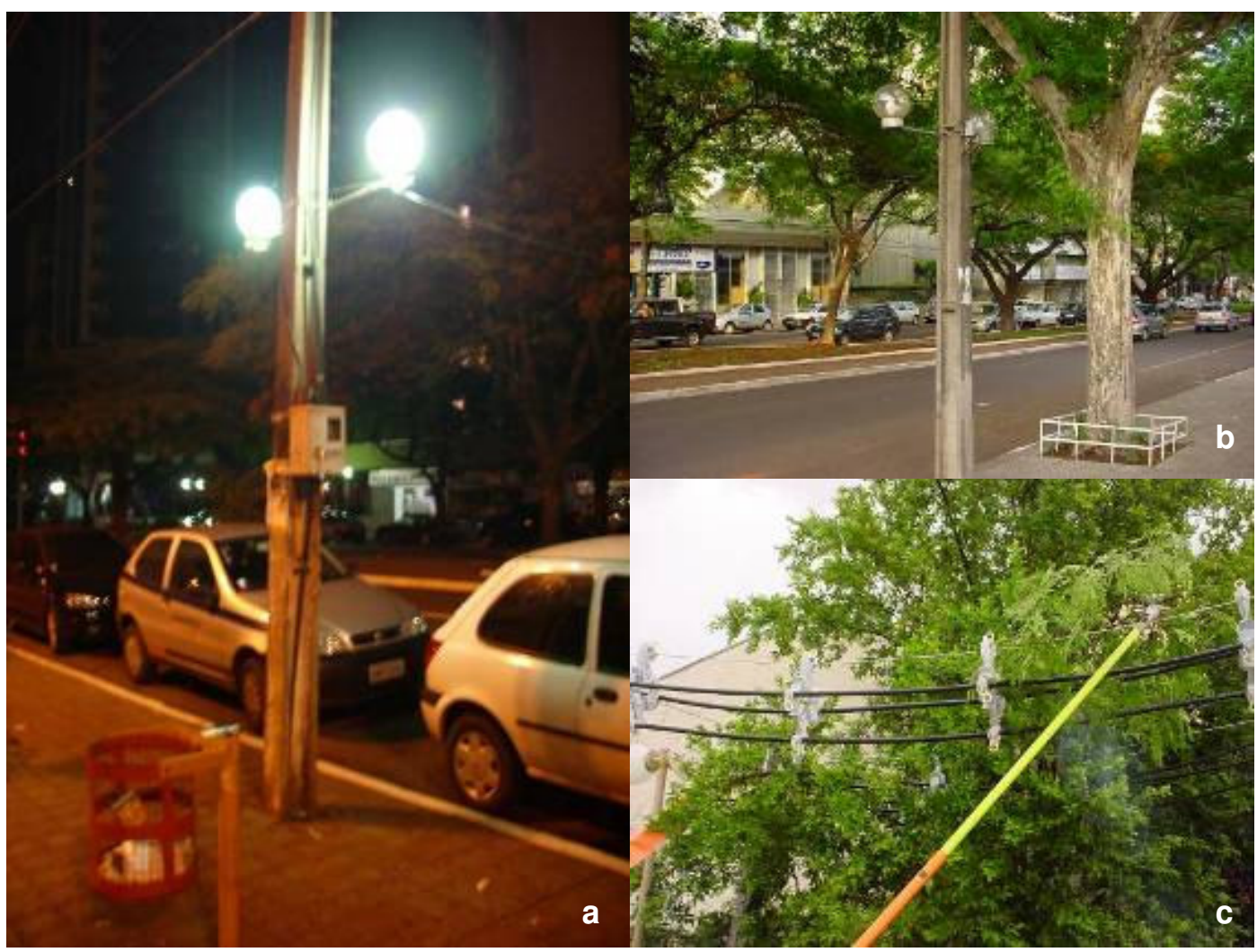

Figura 11. Nestas imagens nota-se como a cidade de Maringá/PR resolveu dificuldades da manutenção de uma iluminação pública eficiente, dos sistemas de distribuição de energia e da conciliação com a arborização de porte alto: a e b- rebaixando a iluminação e cprotegendo a fiação aérea. 


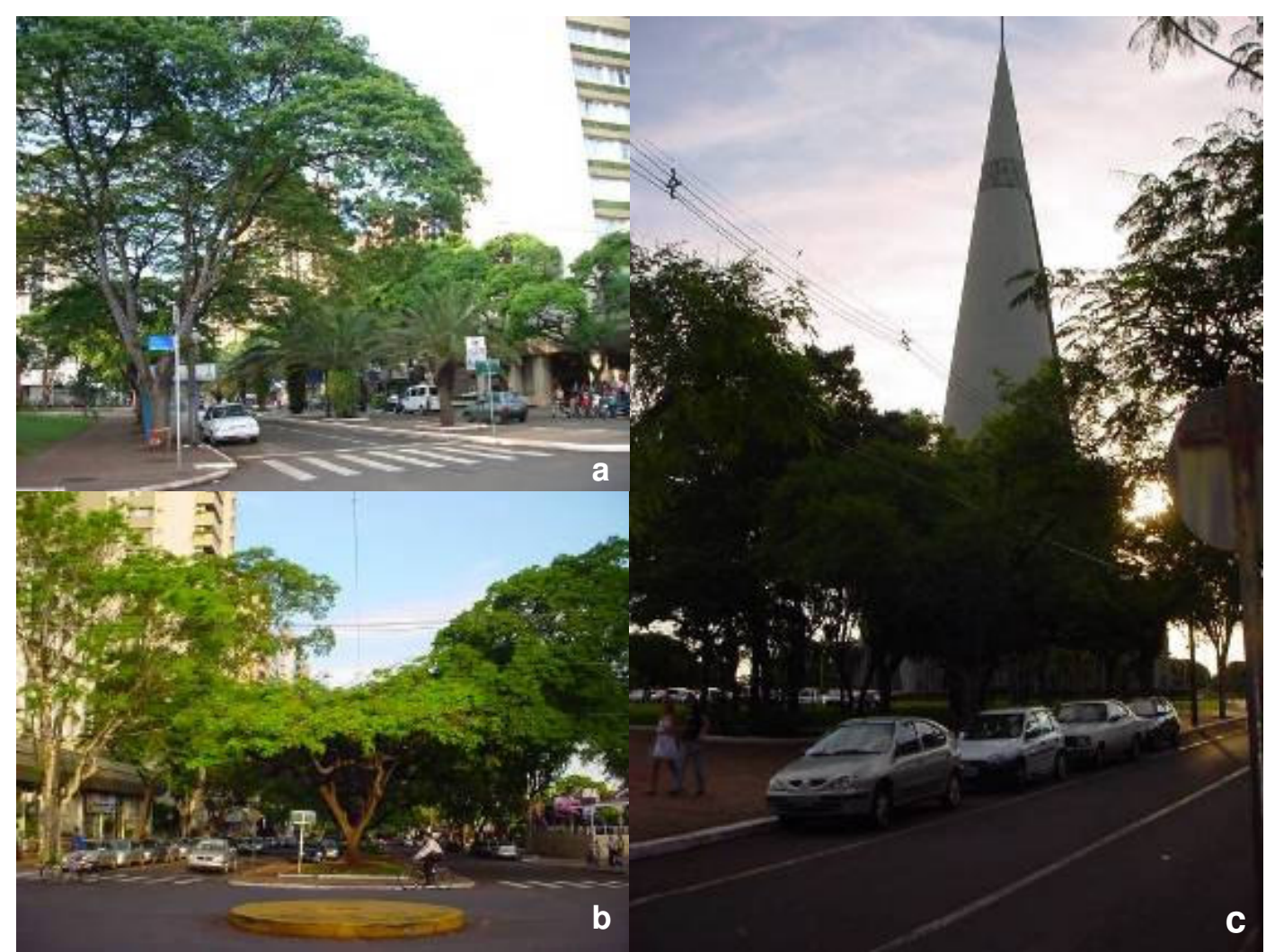

Figura 12. Arborização em harmonia com a fiação aérea na cidade de Maringá. a - rede passando entre as árvores; b - Cobertura total das superfícies asfaltadas com a fiação passando sobre as árvores; c - Rede protegida com a utilização de espaçadores, acima da arborização.

\section{DISCUSSÕES}

Inúmeras cidades brasileiras enfrentam o processo de substituição generalizada da cobertura vegetal viária, das árvores de médio e grande porte, por arbustos, arvoretas e espécies de pequeno porte. Esta prática desconsidera os benefícios propiciados pela arborização de médio e grande porte ao microclima e aos cidadãos urbanos. Estas substituições têm sido influenciadas por diversos fatores desde a criação de mitos que consideram incompatível a árvore e o meio urbano, bem como influências e restrições de empresas concessionárias de serviços públicos, notadamente energia elétrica, redes de água, esgoto e, mais recentemente, de gás. Locais antes arborizados e que ofereciam condições agradáveis de vida à população estão enfrentando problemas acentuados pela falta de vegetação. A retirada arbórea em muitas regiões e, a substituição do porte das espécies utilizadas, além de alterar o microclima urbano será responsável pela potencialização dos efeitos das alterações climáticas nas cidades, nas quais somente as árvores poderão auxiliar o homem a resgatar e a manter a sua qualidade de vida. Dentre as 
cidades apresentadas neste trabalho, Piracicaba enfrenta atualmente diversos problemas por haver optado pela substituição de sua arborização, anteriormente caracterizada por espécies de grande porte, por arbustos. O Bairro Cambuí em Campinas é uma representação, embora a intensa retirada arbórea que vem passando, ainda hoje, da presença de árvores de grande porte convivendo harmoniosamente com as construções. Maringá, no Paraná caracteriza-se como o melhor exemplo no sentido da função da arborização, em termos de serviços ambientais e de seus benefícios para as cidades e seus habitantes.

\section{CONCLUSÕES}

- O uso de árvores é muito mais vantajoso que o de arbustos na arborização das vias das cidades, tanto em termos de segurança pública, quanto financeiros, estéticos, climáticos e funcionais;

- Cidades que optaram pela manutenção da arborização de grande porte, têm, atualmente, grande diferencial em termos de qualidade de vida, comparando-se àquelas que optaram pela sua substituição por arbustos, por espécies de pequeno porte, ou ainda, pela não reposição dos indivíduos suprimidos;

- A utilização de árvores no meio urbano poderá reduzir as conseqüências dos fenômenos das alterações climáticas globais cada vez mais vistos;

- O planejamento urbano adequado visando o estabelecimento, o desenvolvimento e a manutenção de uma arborização de qualidade deve ser a meta dos gestores públicos, para oferecerem qualidade de vida a toda à população, como, também, de empresas prestadoras de serviços, preocupadas com a sustentabilidade;

- Em áreas consolidadas pode-se rebaixar a iluminação pública, trocar a rede de energia convencional pela protegida, compacta e subterrânea, cuja viabilidade econômica se dá pelo maior tempo de vida útil do material, alta confiabilidade do sistema e ausência da necessidade da prática da poda de árvores (VELASCO, 2003).

\section{REFERÊNCIAS BIBLIOGRÁFICAS}

GREY, G.W.; DENEKE, F.J. Urban forestry. New York, John Wiley, 1978, 279p. 
LIMA, A.M.L.P. PIRACICABA/SP: Análise da arborização viária na área central e seu entorno. 1993, 238p. Tese (Doutorado em Solos e Nutrição de Plantas) - Escola Superior de Agricultura “Luiz de Queiroz", Universidade de São Paulo, Piracicaba, 1993.

MASCARÓ, L; MASCARÓ, J. Vegetação urbana. 2.ed. Porto Alegre: Mais Quatro Editora, 2005. 204 p.

SILVA, L.F.; LIMA, A.M.L.P.; SILVA FILHO, D.F.; ROLLO, F.M.A. Capacidade de interceptação da chuva em duas espécies, mais evidentes em arborização urbana. In: CONGRESSO BRASILEIRO DE ARBORIZAÇÃO URBANA, 11, Vitória, 2007. Anais... Vitória: SBAU, 2007, CD ROM.

SILVA FILHO, D.F. Sombra também gera economia. Gazeta de Piracicaba, Piracicaba, 21 set. 2006. Dia da Árvore, p.9.

VELASCO, G.D.N. Arborização viária x sistemas de distribuição de energia elétrica: avaliação dos custos, estudo das podas e levantamento de problemas fitotécnicos. 2003, 94p. Dissertação (Mestrado em Fitotecnia) - Escola Superior de Agricultura "Luiz de Queiroz", Universidade de São Paulo, Piracicaba, 2003. 